\title{
Finding Sustainability University-community collaborations focused on arts in health
}

\author{
Mike White \\ Mary Robson \\ Centre for Medical Humanities, Durham University
}

Gateways: International Journal of Community Research and Engagement Vol 4 (2011): 48-64

(C) UTSePress and the authors

ISSN 1836-3393
This article describes a number of community-based arts in health projects in schools and disadvantaged communities in Northern England that connect with the interdisciplinary research interests of the Centre for Medical Humanities at Durham University. In 2000, we were invited to become associates of the newly established centre (at that time, known as the Centre for Arts and Humanities in Health and Medicine). We brought with us a portfolio of arts and health projects, underpinned by a growing funded research agenda. White took up the post of Senior Research Fellow in Arts in Health and Robson became Associate Artist for Arts in Health and Education. We have a background in arts management and practice, often within community health contexts, and with a pedagogic role of facilitating emotional health and wellbeing in schools and communities. Over the last 10 years we have worked to connect the centre's interdisciplinary research interest in what makes for human flourishing with community-based arts in health projects that can advance participatory action research and test hypotheses. We are particularly interested both to examine and demonstrate good practice in community-based arts in health and to assess what factors may help to make the work sustainable for long-term research study.

To assist us in our inquiry, we have so far been able to access through the university several tranches of outreach development funding and 'seedcorn' research grants, supplemented by personal awards of fellowships from the National Endowment for Science, Technology and Arts. This interest and support have helped us to develop an intellectual framework for arts in community health and examine its practice internationally, as well as providing a promotional platform and other funding opportunities. University involvement has also, however, set us a two-fold challenge: to sustain the work both as meaningful arts activity for the participants and as fertile ground for inquiry by researchers. This is carefully nurtured community work and cannot be set up just to test out hypotheses, and it requires longitudinal thinking in its practical development, if not also in its research methodology. 
In this article we set out some lessons learned from our practice, and examine how community-based arts in health is relevant in a broader policy context of education, social cohesion and public health. At the core of our work is assisting schools and communities to develop new traditions that celebrate health awareness and occasions of transition through the power of resonant imagery and the reflective practice that comes from relationship-based work.

\section{THE 'HAPPY HEARTS' LANTERNS: A CASE EXAMPLE}

The use of handmade lanterns in the UK for celebratory processions originated with the theatre company Welfare State International, with whom we worked in the 1980s. Lantern parades have been a connecting thread of imagery throughout our many years of involvement in arts and health projects. They are, literally, occasions to view a community in another light. Sometimes they are one-off events, but in many cases they become annual celebrations and form part of wider programs of work that connect arts, health education and community development. They can provide small-scale but significant practical instances of how social capital is produced and built upon. Lantern events offer a tangible image of how that 'capital' is in circulation in the community. They create potent, resonating images for particular times and places, and literally throw light upon what makes for healthy living. Every neighbourhood should have one.

One such event, the 'Happy Hearts' celebratory lantern parade for the Wrekenton estate in Gateshead, became an annual event that took place each March from 1994 to 2006. Core support came from Gateshead Libraries and Arts, with a succession of charitable trusts and sponsors providing one-off grants. From the outset the event involved hundreds of local children, their families, voluntary agencies, churches and the district health promotion team. Wrekenton is an area that is regarded as a 'black spot' in terms of both its health profile and its media image as a rough place. Yet over the years the procession became the distinctive event in the local calendar, a metaphorical 'screening' and celebration of community health.

During the 1990s we believed that we were helping to develop in Wrekenton a model example of practice in communitybased arts in health. This model addressed both emotional health and physical health through a focus on creating participatory arts activities in a community with just about the worst morbidity record in England for coronary disease. After 12 years of running a highly successful and influential schools and community project channelling health promotion around the annual sculptural lanterns parade, we had to resign ourselves, for pragmatic and complex reasons, to closing it down. Our letter of 27 February 2006 to the new head teacher of the school where the project workshop was based explained why: 
The Happy Hearts Lanterns Parade began in 1994 and has been a hugely successful venture. From humble beginnings, it became a nationally renowned project and example of good arts in health practice, featured in conference presentations around the world and a seminar in Downing Street. Commissioned by Gateshead Council, it transformed from a single event into a robust, annual tradition. Local people took it to their hearts, commemorating births and deaths through it and becoming expert lantern makers in the process. Annual core funding from Gateshead Libraries and Arts was supplemented by grants from charitable trusts, health services and sponsorship. Latterly, the Council grant was somewhat diminished, but their arts team provided invaluable technical support year after year. Happy Hearts brought well over $£ 130,000$ of funding into Wrekenton over those years, and inspired much more, including the community of Southwick in Sunderland who now have their own procession, Catch the Light. Over the years it has provided an important case study for research into the role of local arts development in addressing health inequalities. The aim of Happy Hearts was to work with the community network to help promote inner strength, health and development on every level. It is about sharing. It can only happen in the context of a constantly developing tapestry of relationships. Sadly, for whatever reasons, Happy Hearts is no longer supported by a strong local network and therefore cannot continue. It would be a contradiction in terms for it to do so.

There was no reply to this letter, which in itself spoke volumes for the sorry state into which the initiative had deteriorated. When the event began, there was a wealth of networking in Wrekenton. Each year, teachers, health professionals and local artists learned how to make lanterns at an open day held for all interested parties. Reciprocally, the project team was invited to attend local meetings where schools, churches, community education, social services, the youth service, libraries, health visitors and the police were all represented. These meetings generated more support for the project - a second primary school became involved and a teenage mothers group signed up to make images for the procession; a local computer group produced the poster and the community police officer would organise the route and join us on the parade.

Over the project's last few years, however, the picture became quite different. It had become a battle to get the event to happen at all, for lots of reasons, not simply lack of funding, though that was proving more and more difficult. The biggest concern had been the falling off of the partner agencies that provided year-round community contact and helped us facilitate a meaningful development of the project as it generated its own participant-driven narrative. There were other reasons, too: broad community network meetings no longer happened; changes in schools and agencies meant less of an emphasis on the emotional and social development aspects of the project; the police started to charge a considerable fee to come on the parade; and, whilst 
people from other communities were coming to observe and be involved in the project, it was evident that fewer new local people were signing up to its potential.

The shutting down of Happy Hearts was felt as a personal disappointment to us as we had embedded our belief in the potency of arts in community health within the spirit of this event. Its long duration had assisted the evolution of our understanding of arts in community health as a distinct area of activity operating mainly outside acute health-care settings, being characterised by the use of participatory arts to promote health, as described in White's (2009) book on practice and research in this field. The practice of arts in community health was pioneered in the UK in the late 1980s through sporadic pilot projects placing local arts development in health promotion and primary care contexts. It has since grown and expanded to embrace community health on a broad front, hooking up with multi-agency initiatives to address the social determinants of health through partnership work. In communities and schools in disadvantaged areas it has combined creative activities with health education and amassed positive testimony from participants as to its value.

The big challenge for arts in community health has been to sustain projects for long enough to understand and consolidate the practice and to undertake longitudinal research that can utilise and analyse participants' testimony within a more rigorous ethnographic framework. Inevitably it proved difficult for a parlous community arts project such as ours, reliant on successive one-off project funds, to maintain the necessary on-the-ground partnerships, attract strategic support, and remain vital and engaging within a generational timeframe.

\section{PLACING ARTS IN HEALTH IN A BROADER POLICY CONTEXT}

From a policy point of view, the extinguishing of Wrekenton's lanterns in 2006 was perhaps unfortunately timed. In the public health field, interest was growing in the 'health assets model' (Morgan \& Ziglio 2007). This model contends that, historically, health promotion has worked on a deficit model that focused on the problems and needs of communities to be addressed through health resources. An asset model, on the other hand, looks at communities' capability and capacity to identify problems and activate their own solutions, so building their self-esteem. Public health practitioners were beginning to argue that salutogenic (or health generating) factors that build health awareness through social cohesion and personal meaning are just as important as pathogenic (or sickness generating) processes, particularly as risk factors account for only 40-50 per cent of early mortality (Harrison et al. 2004). Some researchers went so far as to suggest that identifiable health assets in a community could include wisdom, creativity, talent and enthusiasm, and that these revealed cultural and values-based potentiality. Tapping into this potential would 
require new training and reorientation of existing social welfare and economic delivery and development systems which recognised that 'community cohesion may be a very significant value-based asset with cultural determinants' (Harrison, Kasapi \& Levin 2004, p. 9).

Harnessing political will in support of the health assets approach has been more gradual and some of the excitement generated in the public health arena by the idea has been lost in translation. The foundations of the coalition government's 'Big Society' plans in 2010 were, ironically, already being laid in the final term of the Labour government. A framework that could practically assist a health assets approach in public health work with communities was set out in the Department of Communities and Local Government White Paper (2006), which proposed arrangements for local authorities to lead on health and wellbeing issues in local communities. It aimed to shift the pattern of healthcare provision to prevention, with particular attention to complex issues of social exclusion. The White Paper had an accompanying strategy which paved the way for the current culture shift in commissioning by providing opportunities for the voluntary sector to bid to run programs and services. This was a significant strategic change that could assist in introducing arts projects into community care partnerships, based on Local Area Agreements forged between local authorities, primary care trusts and other partners. It placed emphasis on the voluntary sector's ability to assist in needs assessment and capacity-building in communities, and advocated more joint workforce development (Department of Health 2006). Further government support for this shift was provided with the publication of the Department of Communities and Local Government White Paper on Empowerment (2008), which set out how the untapped talent of communities could be unleashed to create improvements to public services, local accountability and opportunities for enterprise. Wrekenton's Happy Hearts missed the boat on this purchaser/provider crossing, possibly because it was a schools-based project which lacked local leadership at the time. Elsewhere in North East England, some social prescribing schemes that were using the arts to address mental health and ageing fared better.

Before this article gets mired in 'what ifs' and 'what could have beens' it is time to report an extraordinary development in Wrekenton that occurred in 2010. A group of residents on the estate approached the local authority and the primary care trust for help to reinstate the annual lanterns event after its five-year hiatus. These were new parents who had participated as children in the early parades, and who now wanted to revive the event for the benefit of their children. They wanted it not just to provide some seasonal festivity in the social calendar but precisely because they grasped its potency as a health promotion tool. They were particularly concerned about recent evidence that Wrekenton had double the national average of smokers at 43 per cent, and that a third of young women on the estate smoked. Furthermore, in 
Gateshead the pre-mortality rates from cancer were among the highest in England, at twice the national average. As one resident commented to the local paper, 'we wanted to do something to bring down these terrible figures in a way that educated but didn't patronise people and that would bring the community closer together. There used to be a Lantern Parade that went through parts of Gateshead that started in the mid-1990s to raise awareness of health matters such as heart disease, so it seemed like an ideal way for us to address the issue of smoking' (Chronicle Extra 2010). The newly formed Lantern Parade Committee subsequently fundraised for an event and engaged artists to work with the community on a parade for national No Smoking Day in March 2011.

We had thought the Lantern Parade project was finished, blighted as we explained in our letter by the collapse of the local organisations' network and the schools' support that we had seen as central to its sustainability. The surprise revival of the event helped us see that there were other overlooked factors that needed to be taken into account in the research and evaluation of arts in community health in respect of sustainability: namely, the resonance within the experience of an art work, the aesthetic agency of participatory arts and what we ascribe to be 'the communal will'. Our logistical problems in sustaining the parades in Wrekenton had perhaps led us to undervalue these effects and to focus instead on inputs and outcomes of social capital. We had assumed that the community no longer wanted this event because the professional 'gatekeepers' had become so uncommitted. Yet the anecdotal evidence of community support, gathered in comments books, was often staring us in the face - for example, in the remark of a teacher with a heart condition who wrote: 'when the big "heart of the community" lantern lit up, my heart felt better'. Similarly, in a nine-year-old boy's literacy in the social determinants of health when he observed that 'when the lanterns light up, everyone becomes my friend'.

Key facets of the aesthetic agency of participatory arts, as acknowledged in an Arts Council England survey (COI 2007), are that they generate wellbeing and help strengthen identity, connection and a supportive sense of place. In parallel with this, there has been growing interest in the public health arena in Antonovsky's theory of 'salutogenesis' (Lindstrom \& Eriksson 2006), which suggests that health originates in the human quest for coherence and a harmonious environment (Antonovsky 1979), a theory which could have application across the whole arts in health field. Through sustained programs of participatory arts, shared creativity can embody committed expressions of public health, simultaneously identifying and addressing the local and specific health needs in a community. Importantly, this collective action still proceeds from the personal, facilitating engagement by individuals with their own health needs, but also creating 
commitment to a communal will for a shared experience. This was recognised at the launch of the National Health Service in 1948 by its political architect, Aneurin Bevan:

The maintenance of public health requires a collective commitment. Preventative medicine, which is merely another way of saying collective action, builds up a system of social habits that constitute an essential part of what we mean by civilisation (Department of Health 2000, p. 4).

Bevan acknowledged that there is a cultural base to the health services and that we need to make this visible in order for the public to fully engage with it and help shape it. Yet it has taken half a century to realise that participatory arts could have a role in bringing this to light. A commitment to addressing the social determinants of health requires a process of engagement that goes beyond the health services themselves and builds alliances for social change. This in turn can provide a significant opportunity for a university to engage meaningfully with its host communities in the development of social capital. In Bevan's statement there are glimpsed the rudiments of social capital and resilience.

The term 'social capital' has become a confusing and overused term in assessing the impact of community development initiatives (McQueen-Thomson \& Ziguras 2002). In the context of community arts, a better understanding of the social psychology that goes into building trust and reciprocity within communities may be found in a book that predates social capital theory: Lewis Hyde's (1979) seminal work on art and the gift economy, The Gift. Hyde contrasts the sterile exchanges of commodity culture with the ability of an artwork or totem to bind a community through an evolving tradition of reciprocal generosity. Making art work as a social gift is at the heart of thinking and practice in community arts. A gift is not a commodity at all, in the sense that its value is perceived wholly in the transmission rather than in the accumulation of a good. What matters is the sentiment and ceremony of the process. As Hyde describes it:

When a gift passes, it becomes the binder of many wills. What gathers in it is not only the sentiment of generosity but the affirmation of individual goodwill, making of those separate parts a spiritus mundi, a unanimous heart, a band whose wills are focused through the lens of the gift. Thus the gift becomes an agent of social cohesion, and this again leads to the feeling that its passage increases its worth, for in social life at least, the whole is greater than the sum of its parts (Hyde 1979, p. 36).

Hyde emphasises the importance of a process of emotional transaction through creative participation that makes for genuine empowerment rather than a balance sheet deduction of how much social or cultural capital a community may possess.

Anthropology can provide an interesting lens for examining the effects of arts activities on health promotion and population health. In Homo aestheticus, US art critic Ellen Dissanayake 
(1992) argues that species-centred art is a behaviour, a biological necessity, which is disciplined by the need to do what feels good in art-making. She considers ritual and art to be socially reinforcing, with ceremony having evolved as a survival mechanism that binds people together. A distinctive quality of art that she terms 'making special' is thus a form of social persuasion, turning what is obligatory for survival into something desirable, and addressing substantive communal concerns through evoking deep feelings. These ideas are highly relevant to the practice of arts in community health, and there may be a fundamental connection to be explored between creativity and health as a pathologically optimistic expression of survival. Dissanayake refers to 'liminal' transitional experiences producing 'communitas' (the feeling of community). This state of being also relates to Csíkszentmihályi's (1996) theory of 'flow', when action and awareness fuse and ego is replaced by a collective sense of 'rightness' which can channel and relieve anxiety or distress. By having control of the process, Dissanayake argues, it becomes possible for participants to speculate and to see the relation of the present ceremony to past and future, a form of scenario building. Dissanayake (1992, p. 83) concludes "the reason art is "therapeutic" has at least as much to do with the fact that, unlike ordinary life, it allows us to order, shape and control at least a piece of the world as to do with the usually offered reason that it allows sublimation and self-expression'. It is this therapeutic effect which motivates participants to repeat these events, creating traditions. These alert us to 'selectively valuable behaviours', so that choice and community go together.

A motivation to healthier living also proceeds from emotional response to reciprocal trust. Participatory arts can provide a channel for that to be celebrated, and artists working in this field consistently say that in facilitating this they want to make a difference to people's health because they genuinely care. Artistic processes may confound the scrutiny of clinical examination, health policy review or evaluation technique, yet there is a benefit staring us intellectually in the face. The collective art work comes to express temporarily a shared creativity that still allows for personal pride of attainment, and may produce varied and deeply personal meanings for the participants. That is why participants instinctively so often 'get it' when professional observers may not. Their emotional response is the embodiment of meaning; a phenomenon which is now considered central to cognitive science. As philosopher Mark Johnson (2008, pp. 46-47) asserts:

We need to know how emotion binds us to the world, helps appraise our experience, and makes action possible. One of the surprises in studying these deep, pre-reflective, emotion-laden, embodied aspects of meaning, conceptualisation and reason is that these turn out to be the very processes and elements traditionally explored in aesthetics and art theory. 
Although this phenomenon may not yet be proven to have a replicable therapeutic effect on individual pathology, it does demonstrate how a benign communion around health awareness can be created and sustained in people and places; and in our experience, even in communities enduring socioeconomic disadvantage.

Just as 'social capital' has become a rather over-used term, so 'resilience' has become a shallow watchword for the sustainable self and community in times of adversity. A Canadian handbook providing an excellent overview of the complexity of evaluating resilience in children states that 'resilience has come to mean the individual capacities, behaviours, and protective processes associated with health outcomes despite exposure to a significant number of risks' (Ungar 2005), but it later cites Glantz and Sloboda's (2009) observations on resilience, concluding that 'there is great diversity in the use of the concept; it is used variously as a quality, a trait, a process or an outcome' (Ungar 2005 , p. 110). Ungar argues that 'resilience' is a concept that is difficult to generalise because an understanding of the specific social and cultural context is crucial and it requires mixed methods of research that account for the multiplicity of competing understandings of health, inevitably requiring interpretation and the use of metaphor. The core argument is that it is more than an individual trait because 'resilience occurs when the personal meets the political, when the resources we need for health are available so we can realize our potential. We need a communitization of health, understanding health as a communal experience. Resilience is simultaneously a quality of the individual and the individual's environment' (Ungar 2005, p. xxiv). Ungar also notes that both psychological and political influences are needed to effect change in community health, and this has been particularly neglected in professional health practice with children - at least until recently in the UK.

\section{ADDRESSING CHILDREN'S WELLBEING THROUGH ARTS IN HEALTH}

The Labour government's Every Child Matters strategy, introduced in 2000, identified five national outcomes that all professionals working with children and young people needed to be aiming for: these are being healthy, staying safe, enjoying and achieving, making a positive contribution, and socioeconomic wellbeing (DfES 2005). The strategy provided a context in which to conduct joint conversations, joint planning and joint working by statutory and voluntary agencies, with clear processes to achieve those outcomes for children and young people; but crucially children and young people had to be involved in learning to take responsibility for achieving those outcomes for themselves. The National Children's Bureau came to see those five outcomes as integrated rather than separate (Worthy 2005), and identified the characteristics of good practice as residing particularly in projects that fostered creativity 
and emotional and social development. Such projects can ameliorate the process of transition, not only as it occurs in the school system but also possibly when a child undergoes difficult change and loss in their personal life.

What may now affect change in both child and community health practice in the UK is The Marmot Review Fair Society, Healthy Lives (2010), which has attracted interest across the political spectrum, and is endorsed at the outset of the Public Health White Paper, Healthy Lives, Healthy People (Department of Health 2010). The Marmot Review sets out six policy objectives to reduce health inequalities, including 'Enable all children, young people and adults to maximise their capabilities and have control over their lives', with a priority to 'ensure that schools, families and communities work in partnership to reduce the gradient in health, well-being and resilience' and 'create and develop healthy and sustainable places and communities'. The review spells out that differences in health status come down to economic inequalities. On the social determinants of health it concludes 'All these influences are affected by the socio-political and cultural and social context in which they sit' (Marmot 2010, p. 10). It encourages extending the role of schools into communities and developing the education workforce to address social and emotional wellbeing in school, family and community life. The review notes that family life has more influence on a child's educational development than school itself and concludes 'The physical and social characteristics of communities, and the degree to which they enable and promote healthy behaviours, all make a contribution to social inequalities in health'. It calls for support for communities to find their own whole system solutions so that top-down approaches are reduced and 'avoid drift into small-scale projects focused on individual behaviours and lifestyle' (Marmot 2010, p. 18).

The Marmot Review stresses how working in partnership can scale up interventions. In recent years our schools-based arts in health projects (and at last count we are variously working with 24 schools) have been brought together in an annual review meeting at The Wolfson Institute in order to learn from each other's practice and to set a framework for exchange visits and the scaling up of activity into a common program. The university had a facilitating role in enabling focused conversation to take place between academics, schoolteachers and participants, enabling us to refine together the proposals that we intend to present to major research charities and research councils in the coming year. We have also attempted to nurture a network for engagement in a longitudinal study.

One of the most influential of our community arts in health and education projects is now in its eighth year: 'Roots and Wings', based in a primary school in Chickenley in West Yorkshire. Chickenley is a socioeconomically deprived 'sink estate' on the outskirts of Dewsbury. Its primary school has had a troubled recent history, with a record of low academic achievement and 
uncommitted teaching staff - some children had experienced as many as 14 different class teachers in five years. As a result, in 2001 it was taken into 'special measures' on the recommendation of the inspectorate. A newly installed head teacher saw the potential in having artists in residence at the school to help address its difficulties, to be funded initially through the Children's Fund. The project's artists, led by Robson, have worked year-round with pupils, their families, school staff and the wider community to foster social and emotional development and encourage cultural change through new traditions that mark significant moments in the life of the community.

At the core of Roots and Wings is the art room, a space run by the children during breaks and lunchtimes with artist support. Children choose to make things of emotional content in these sessions. Encouragement to reflect on feelings has led to the children creating greetings cards, initially for friends and family but now also for sale in craft outlets in the town, with the proceeds providing charitable donations that the children determine. Sometimes there may be as many as 40 children in the art room, but order emerges in this bedlam as children assist each other in realising their art from concept to appraisal. It is not just an activity room; it is a space to foster empathy, and to model and analyse relationships in a child-friendly way. The art room also provides a congenial space that has influenced the design of other areas in the school.

Within three years, the Roots and Wings program had significantly impacted on Chickenley Primary's performance at all levels. An Ofsted inspection report (Kirklees LEA 2006) stated:

One child wrote about her marvellous work of art, 'I think I am a painter now. I could work in a fast food restaurant, but being a painter is better'. Pupils are cherished as individuals. Education for personal, social, health and citizenship is well organised to promote healthy and safe lifestyles. The initiative entitled 'Roots and Wings' is an outstanding element which has raised the school's profile locally. Pupils' artistic skills, writing and personal development, for example, are enhanced by its many superb activities. Pupils who are talented in sports or the arts thrive on a curriculum which offers many worthwhile opportunities in these areas. This is reflected in their trusting attitudes and confident bearing.

And one inspector wrote to the children to say:

We loved talking to you about the way that your school has improved in the last few years. The 'Roots and Wings' project is marvellous. We particularly liked the art room and all that goes on in there.

A number of events take place each year that are now accepted and welcomed elements of Chickenley culture. There are two annual carnivalesque parades that celebrate transition. One is held when the youngest children move up to 'big school' and the other with the eldest, as they prepare to begin life at the high school. Every March, children and their parents transform their 
schoolgrounds into a candle-lit representation of their estate for an event known as 'Lantern Land'. Other activities include projects to raise aspirations, encourage effective thinking and increase self esteem - and how to apply these qualities and skills to other areas of life. Every aspect of the project involves reflective practice, whether between the professional practitioners or the pupils.

This seedbed of reflection is a nurturing environment for the professionals involved in Roots and Wings. Their practice places at the heart of everything they do a belief that curiosity is the fuel of development. Modelling congruent behaviour is constant and is crucial to the project's success. While some professional talk will be of attainment, resilience, attendance and expectations, the quality of such projects as these is in the relationships they foster, and in the creation of a fund of memories, both individual and collective, that is helping to redefine perceptions of the community.

Given this reflective environment, developed over years, it came as something of a deflating disappointment to realise that all was not well. A new senior management team had brought changes to the school, as is and should be expected. There were glitches with their understanding of the project and what it brought to the working environment of the school. Other staff changes inevitably added to the misunderstanding as they were not inducted as to Roots and Wings' role much beyond that it produced fantastic art work. The overall relationship between project staff and school staff was amiable, yet somewhat diminished. Without attention, relationships can and did falter. Here was another aspect of the problem we had faced at Wrekenton, but this challenge felt enormous. Wrekenton was an annual event. This was longitudinal work of a rich and detailed nature and so a lot more was at stake.

Project staff felt the problem to be an ethical one since, fundamentally, it was impossible for the work to develop without a mutually understood communal will. The way forward was to talk to senior management and explain that the project would not seek further funding and why. It required a frank, honest yet sensitive approach. This was a no-blame situation but everyone's responsibility. The news of the developments at Wrekenton helped fuel some doubts in us. Were we, the professionals, making decisions at the expense of participants and did we have the right to so do?

It is fair to say that the revelation came as a shock to the senior management. They had no idea that the problem existed and found it impossible to imagine the school without Roots and Wings. The new head teacher declared that the nurturing environment provided by the project was crucial for the children and their ability to learn. What the project team had thought to be a full stop was a semi-colon, a necessary pause. The announcement of a possible closure quickly turned into a conversation that opened up channels of communication. Both sides were able to admit responsibility without rancour and to move on to a new phase of development; the project continues as a 
result and to everyone's credit. That the project enjoys such a rich, reflective environment meant that the situation was called out in time, before it sank to a point of no return. This was not a repeat of the Wrekenton situation; it was progress and indeed sustainability.

\section{OFFSHOOTS OF THE PROJECTS}

Given the longitudinal nature of the work, there is already an accumulated wealth of data from our projects clearly demonstrating how arts-led approaches can contribute to mental health and wellbeing work in schools (Raw 2006). Arts practice is now helping to shape educational practice on different levels, and the links between professionals and academics and participants are now many and varied, as the following examples suggest:

- In the Centre for Medical Humanities ( $\mathrm{CMH})$ we are co-authoring book chapters and articles with our research fellows and $\mathrm{PhD}$ students, based on our fused interests, thereby creating other layers of interdisciplinary working and ways of sustaining interest in and debate about the CMH's work.

- The original evaluator of Roots and Wings has become a PhD student at $\mathrm{CMH}$, pursuing interests in the empathic nature and skills-base of arts and health practice. Her field research will be based on several of our projects.

-As part of an aspirations project, an Associate Dean from Huddersfield University was invited to Chickenley to be interviewed by the children about her job. In response, she invited the children to the university where they visited the 'research gym' and met with professionals, academics and students.

-A Year 6 teacher at Chickenley now works regularly alongside Robson in providing training in 'The Nurturing Curriculum' to teachers in the Kirklees district through the borough's Targeted Mental Health in Schools (TaMHS) initiative.

-The Open University (2009) chose Roots and Wings for a filmed case study to accompany its interdisciplinary course in Critical Practice with Children and Young People, a module masterslevel course that provides a deeper understanding of the ideas that influence current practice, analyses recent changes in the organisation of services and explores what it means to be a critical, reflective practitioner (Robb \& Thomson 2010).

-Academics from the Anthropology and Geography departments at Durham have visited Roots and Wings on several occasions and show an ongoing interest in the possibility of future research collaborations with practitioners and participants.

These sustained relationships make for a complex network: practitioners, participants and academics meet in safe and comfortable spaces, allowing for mutual understanding that can help to originate participatory and guided research with mentoring from various departments within Durham University.

The projects themselves also generate more research-guided practice. Loca is Kirklees Council's arts and regeneration agency. Inspired by Roots and Wings' successes, the agency was keen to 
extend to other schools some of the working practices that were proving so successful in Chickenley. Loca successfully bid for funding to develop 'Inside Me', a program which for its first three years involved artists working in a cohort of six primary schools to deliver a series of 18 short projects with a particular focus on emotional literacy and emotional health. On the strength of the impacts and strong evidence base generated (Loca 2009), Kirklees Primary Care Trust offered funding to extend and deepen the work, enabling a program which saw five artists placed in four primary schools and one secondary school for two years on an 'in residence' basis. This in turn led to the Primary Care Trust commissioning Loca to be a delivery partner in the new Kirklees TaMHS program. Loca's creative input to this 10-month program involves some of the most experienced artists from Inside Me and Roots and Wings working alongside other specialists (including a primary mental health worker, educational psychologists, Social and Emotional Aspects of Learning specialists) to find innovative and creative interdisciplinary ways of delivering interventions and training with children and staff in 15 participating schools (only one of which has previously been involved with Inside Me).

In respect of the Inside Me work in the two years prior to TaMHS, Kirklees Primary Care Trust was not interested in yet more of the kind of evaluation (focused on proving the work's emotional health impacts with children) which had persuaded it to invest in the work in the first place. So Loca invited academics from the Centre for Medical Humanities to a study day to examine the data and generate ideas for differently focused discussion, reading and writing. The resultant papers and articles are a way of sustaining interest in and thinking about the work and retaining a relationship with academics; an alternative to an evaluation report that might never have seen the light of day.

\section{CONCLUSIONS}

Sustaining a long-term relationship with projects like those we have described also allows both the quantity and quality of documentation and dissemination to be improved. Such work lends itself readily to interdisciplinary analysis as well as generating a richly detailed evocation of the process of the work, so that participants' tales become vital testimony. The emergent narrative in a community about a continuing seasonal celebration assists our understanding of the resonance and aesthetic agency of arts in health that we referred to earlier. For example, when we asked a group of women volunteers whether the lanterns had any significance for them after the event, they replied in unison 'They're our memories'. This home-grown testimony helps to build the persuasive advocacy for an arts in health project to be sustained through difficult times. It is important to look through and beyond the evidence because as the World Health Organization (2008 p. 33) has observed, 'evidence is only one part of what swings policy decisions - political will and institutional 
capacity are important too. But more than being simply academic exercises, research is needed to generate new understanding in practical, accessible ways, recognising and utilising a range of types of evidence, and recognising the added value of globally expanded Knowledge Networks and communities.'

Despite the present economic climate of austerity, there is still fertile ground on which arts in community health and university research can engage. In a pressured voluntary sector, schools with a commitment to supporting community development may become key partners and locations from which to explore a viable 'Big Society'. Creating 'communitas' in neighbourhoods is going to require far more than recreational volunteering if the coalition government's 'Big Society' idea is to redress the effects on local services of what author and libraries campaigner Philip Pullman (2011) has tellingly described as 'market fundamentalism'. Long-term partnerships between restructured local health services, academy-style schools with a social agenda and whatever cultural services have been spared the axe could be crucial - and university involvement could help motivate such partnerships to common ends in practice and research. Methods of knowledge exchange and transfer will need to become more about entrepreneurial ingenuity and low resource requirement, and about releasing staff for volunteering than applying full economic costing for research.

As England's public health function is now being transferred to local authorities, strategies to deliver on community health must remain sensitive to local culture and circumstances or the inherent advantage of having local authorities as a commissioning nexus for services relevant to local population needs may be lost. As evidenced in Happy Hearts and other projects described in this article, effective health promotion is about more than addressing topical health issues and priorities, it is also about issues of identity, meaning and place - and these are essential factors in the development of arts in community health, in expressing the ethos of healthy schools, and in maintaining what Bertholt Brecht described as 'the greatest art of all; the art of living together' (Willett 1964, p. 276).

\section{ACKNOWLEDGEMENTS}

The authors would like to gratefully acknowledge the cooperation and support over many years of the residents of the Wrekenton and Springwell estates in Gateshead, Loca cultural development agency, and the staff and pupils of Chickenley Primary School in Dewsbury.

\section{REFERENCES}

Antonovsky, A 1979, Health, stress and coping, Jossey-Boss, San Francisco, CA.

Central Office of Information (COI) 2007, The Arts debate: Regional consultation meetings, COI, London. 
Chronicle Extra 2010, 'Lanterns aim to light way to health', Newcastle Chronicle Extra, 15 September, p. 6.

Csíkszentmihályi, M 1996, Creativity: Flow and the psychology of discovery and invention, Harper Perennial, New York.

Department of Communities and Local Government 2006, Strong and prosperous communities: The local government White Paper, The Stationery Office, London.

Department of Communities and Local Government 2008, Empowerment: The local government White Paper, The Stationery Office, London.

Department for Education and Skills (DfES) 2005, Every child matters: An overview of cross-government guidance, DfES, London.

Department of Health 2000, The report of the Chief Medical Officer's project to strengthen the public health function, Department of Health, London, p. 4.

Department of Health 2006, No excuses. Embrace partnership now. Step towards change! Report of the Third Sector Commissioning Task Force, Department of Health, London.

Department of Health 2010, Healthy lives, healthy people, The Stationery Office, London.

Dissanayake, E 1992, Homo aestheticus: Where art comes from and why, University of Washington Press, Seattle, WA.

Glantz, M \& Sloboda, Z 1999, 'Analysis and re-conceptualisation of resilience', in M Glantz \& J Johnson (eds), Resilience and development: Positive life adaptations, Plenum Publishers, New York, pp. 17-83.

Harrison, D, Kasapi, E \& Levin L 2004, Assets for health and development: Developing a conceptual framework, European Office for Investment in Health and Development, London.

Hyde, L 1979, The gift: How the creative spirit transforms the world, Routledge, New York.

Johnson, M 2008, 'Body meanings', New Scientist, 12 January, pp. 46-47.

Kirklees Local Education Authority (LEA) 2006, 'Ofsted Inspection 282150', Kirklees Education Authority, Huddersfield, UK.

Lindstrom, B \& Eriksson, M 2006, 'Contextualising salutogenesis and Antonovsky in public health development', Health Promotion International, vol. 21, no. 3, pp. 238-44.

Loca (2009), Inside me: Evaluation report April 2008 - March 2009, Loca, Dewsbury, UK.

Marmot Review 2010, Fair society, healthy lives: Strategic review of health inequalities in England post-2010, The Marmot Review, London.

McQueen-Thomson, D \& Ziguras, C 2002, Promoting mental health and wellbeing: A review of literature focussing on community arts practice, Vic Health, Melbourne, Victoria.

Morgan, A \& Ziglio, E 2007, 'Revitalising the evidence base for public health: An assets model', Global Health Promotion, vol. 14, no. 2, pp. 17-22.

Open University 2009, 'K802 Critical practice with children and young people', course, viewed 8 February 2011, www.open.ac.uk/study/ postgraduate/course/k802. 
Pullman, P 2011, 'Market fanatics will kill what makes our libraries precious', The Guardian, London, viewed 8 February 2011, www.guardian. co.uk.

Raw, A 2006, Chickenley Creative Kids Project: Independent evaluation for year 3, Children's Fund, Dewsbury, UK.

Robb, M \& Thomson, R 2010, Critical practice with children and young people, Policy Press, Bristol, UK.

Ungar, M 2005, Handbook for working with children and youth: Pathways to resilience across cultures and contexts, Sage Publications, London, p. xvi.

White, M 2009, Arts development in community health: A social tonic, Radcliffe, Oxford, UK.

Willett, J 1964, Brecht on theatre: The development of an aesthetic, Hill and Wang, New York, p. 276.

World Health Organization (WHO) 2008, Closing the gap in a generation: Health equity through action on the social determinants of health, $\mathrm{WHO}$, Geneva.

Worthy A 2005, 'Supporting children and young people through transition', Spotlight briefing, National Children's Bureau, London. 